\title{
Modeling and Simulation of Digital Frequency Relay for Generator Protection
}

\author{
Muhammad Mohsin Aman ${ }^{1}$, Ghauth Bin Jasmon ${ }^{1}$, Hazlie Bin Mokhlis ${ }^{1}$, \\ Qadeer Ahmed Khan ${ }^{2}$, Ab. Halim Bin Abu Bakar ${ }^{1}$, Mazaher Karimi ${ }^{1}$
}

\begin{abstract}
Modeling tools are useful for educational and industrial use. Such tools help the new engineers to simulate the power system under normal and faulted conditions. This paper presents the design and various data conversion steps of a digital frequency relay. The designed relay will cover both over and under frequency conditions. The digital relay has superiority over electromechanical relay in terms of accuracy and speed. The large frequency variations could lead to complete power system blackout. History has seen several blackouts due to frequency instability, either due to supply-demand unbalance or $\mathrm{N}-1$ contingency. After distributed generation and the possible islanding issues, frequency relay has again gain the attention of the researchers and industrialists. The performance of proposed digital frequency relay will be observed under different system dynamics on MATLAB/ SIMULINK®.
\end{abstract}

Keywords - Frequency Relay; Swing Equation; Relay Modeling.

\section{INTRODUCTION}

$\mathrm{S}_{\mathrm{s}}^{\mathrm{t}}$ tability of system is one of the major issues of power system. Voltage, Angle and Frequency instability are the basic instability problems [1]. After power system restructuring and the incorporation of distributed generation in power system, stability and protection coordination issues have become a centre of concern for power researchers. Modelling tools are utilized to simulate the system and see the possible impacts during abnormalities. MATLAB, most widely used educational and research software, is also among these tools [2-4]. However, currently MATLAB power system library has no tool box for power system protection. In this paper, a digital frequency block is designed. The design block offers flexibility in terms of further research and improvement.

Frequency instability problem arises when there is a large mismatch between demand and supply or due to N-1 contingency. Mechanical power is produced from turbine and transferred to the generator shaft. A generator converts

\footnotetext{
${ }^{1}$ Muhammad Mohsin Aman, Ghauth Bin Jasmon, Hazlie Bin Mokhlis, $\mathrm{Ab}$ Halim Bin Abu Bakar and Mazaher Karimi are working with University of Malaya, Malaysia. First author can be reached at mohsinaman@gmail.com.

${ }^{2}$ Muhammad Qadeer Ahmed Khan is working with ENI Corporate University, Italy. He can be reached at qadeer88@gmail.com.
}

the mechanical power into the electrical power $P_{e}$. Mechanical Torque $T_{m}$ is created on the turbine from the water or steam power and electrical torque $T_{e}$ is as a result of load connection. The difference between the two torques (known as acceleration torque), causes the fluctuation on the generators speed, and thus resulting in speed variation of the frequency of the power system.

The swing Eqn. (1) demonstrates the relationship between the deviation of the torque and variation of angular acceleration [5].

$$
\begin{array}{r}
J \frac{d \omega}{d t}=T_{m}-T_{e} \\
J \omega_{m} \frac{d \omega}{d t}=P_{m}-P_{e}
\end{array}
$$

Where $J$ is the total moment of inertia of the rotor mass, $\omega_{\mathrm{m}}$ is the angular mechanical velocity, $P_{m}$ and $P_{e}$ are the mechanical and electrical power, given by Eqn. (3).

$$
P_{m}=\omega_{m} T_{m} \quad ; \quad P_{e}=\omega_{m} T_{e}
$$

A normalized inertia constant $(H)$ is defined as:

$$
\begin{gathered}
H=\frac{\text { Stored kinetic energy at sync. speed }(M J)}{\text { Generator } M V A \text { rating }} \\
H=\frac{J \omega_{s}^{2}}{2 S_{\text {rated }}}
\end{gathered}
$$

If $P$ is the number of poles in synchronous machine then the mechanical speed $\left(\omega_{m}\right)$ is related to the electrical speed ( $\oplus)$ by Eqn. (6)

$$
\omega=\frac{P}{2} * \omega_{m}
$$

Substituting Eqns. (5) and (6) into Eqn. (2) results in

$$
\frac{2 H}{\omega_{s}} \times S_{\text {rated }} \times \frac{d \omega}{d t}=P_{m}-P_{e}
$$

Dividing the Eqn. (7) by $S_{\text {base }}$

$$
\frac{2 H}{\omega_{s}} \times S_{\text {rated }} \times \frac{d \omega}{d t}=\frac{P_{m}}{S_{\text {base }}}-\frac{P_{e}}{S_{\text {base }}}
$$


Now, the Eqn. (8) can appear in per unit

$$
\frac{2 H}{\omega_{s}} \times \frac{d \omega}{d t}=P_{m(p u)}-P_{e(p u)}
$$

Where $P_{e}(\mathrm{pu})$ and $P_{m}(\mathrm{pu})$ are the per unit electrical power and mechanical power.

From Eqn. (9), the relation between change in frequency and power could be developed, given by Eqn. (10).

$$
\frac{d f}{d t}=\frac{f_{n}}{2 H} \times \Delta P
$$

Where $f_{n}$ is the system frequency or rated frequency. From Eqn. (10), it can be observed that the mismatches between demand and supply results in frequency change. Thus in order to measure the real time power frequency, different techniques have been developed namely; Newton method; level crossing technique; modified zero-crossing technique least-square error technique; Discrete Fourier Transform (DFT); leakage effect technique; Kalman filter technique; and phasor-based technique and Prony Method [6-7]. However in practical system, most of the relays worked on the principle of zero crossing detection [8-9].

\section{OVER-UNDER FREQUENCY RELAY}

Frequency relay is commonly used in order to protect the power system from blackout in case of major generation/load loss or during N-1 contingency. The relay is also used to detect the islanding operation. Islanding operation normally occurs in case of distributed generation due to loss of mains. The resulting system consisting of distributed generator and local load is often known as "Power Island". This presents a threat to the system in terms of power balancing and controlling. A major threat comes when the power island is reconnected to the rest of the system without synchronising first. Loss of mains is often detected by measuring rate of change of frequency (ROCOF). However ROCOF method cannot reliably discriminate between changes in frequency due to loss of mains and changes due to other disturbances [10]. In [10], the author has also proposed the comparison of rate of change of frequency (COROCOF) for loss of main protection.

Stable frequency operation is always demand of customer. Different countries have their own grid codes to ensure that the quality (voltage and frequency) of electricity supply is maintained within specified standards. For example, in UK following the Electricity Supply Regulations 1989 and the Grid Code the frequency delivered to the consumer must not vary more than $\pm 1 \%$. Also $\pm 6 \%$ variation in voltages is allowed below $132 \mathrm{kV}$ whereas $\pm 10 \%$ regulation is allowed for voltages higher than $132 \mathrm{kV}$ [11].

\section{Modeling OF Digital FREQUenCy Relay}

The Digital Frequency Relay consists of two parts, Frequency Measuring Unit (FMU) and Under-Over Frequency Detection Element (FDE), as shown in Fig. 1. FMU is used to measure the digital value of frequency from the PT while FDE takes appropriate action based on OverUnder frequency limit.

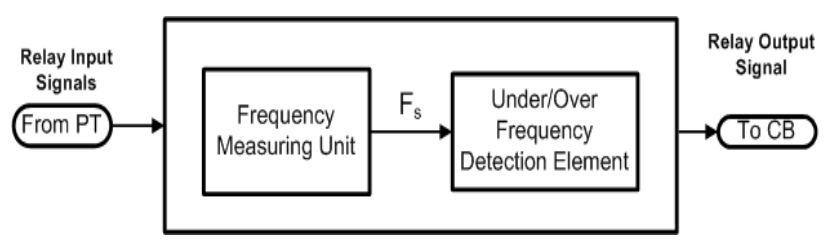

Fig. 1. Block Diagram for Implementing Over-Under Frequency Relay

\section{A. Frequency Measuring Unit (FMU)}

The FMU is used to measure the frequency of a voltage signal from the Potential Transformer (PT). To measure the frequency, the time difference between the two consecutive zero crossing ( $T 1$ and $T 2)$ is measured, as shown in Fig 2.

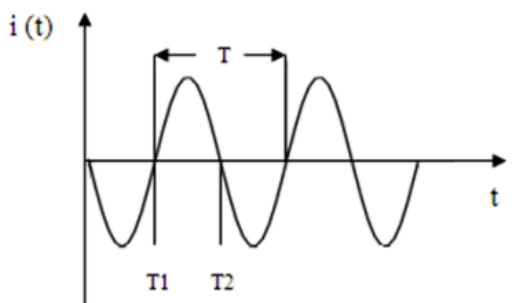

Fig. 2. Measuring Frequency of a Signal

However to measure the total time of a complete waveform, the difference between $\mathrm{T} 1$ and $\mathrm{T} 2$ is multiplied by factor of 2, as shown in Eqn. (11).

$$
\begin{gathered}
T=2 \times\left(T_{2}-T_{1}\right) \\
\text { Frequency }=\frac{1}{\operatorname{TimePeriod}(T)}=\frac{1}{2\left(T_{2}-T_{1}\right)}
\end{gathered}
$$

The FMU unit implemented on SIMULINK is shown in Fig. 3.

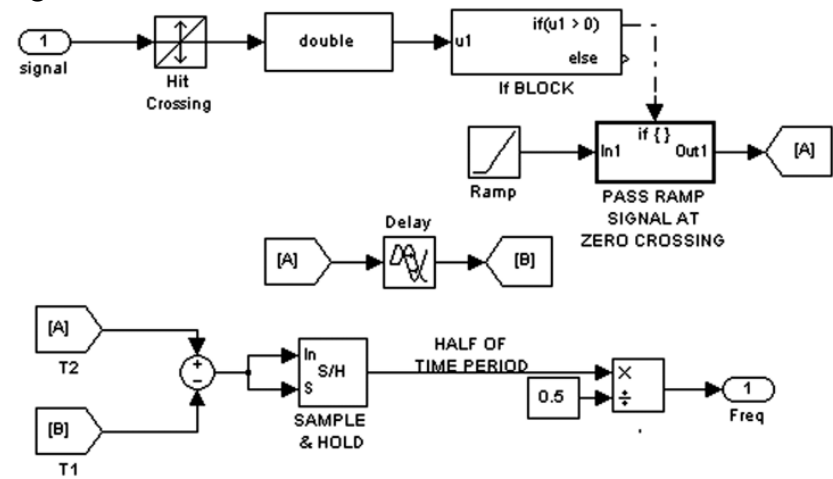

Fig. 3. Measuring Frequency of Voltage Signal on Simulink ${ }^{\circledR}$. 
'Hit Crossing' block is used to detect the zero crossing. The block passes the input signal at its zero crossings to the 'if' block, which in starts sending ramp signal to the output. The time duration of generated ramp is measured and saved to a variable ' $\mathrm{A}$ '. The variable $\mathrm{A}$ is stored in another variable B using the 'Transport Delay' block and the time of the next zero crossing is measured. Subtracting B from A at any instant will give half the time period whose value is held by the 'Sample and Hold' block, till the next zero crossing. After performing the necessary computations, given by Eqn. (13), the instantaneous frequency is achieved. The output (measured frequency) from FMU sends to the FDE for necessary tripping action, in case of fault.

\section{B. Frequency Detection Element}

The FDE is used to take the necessary action in case of Over Frequency (OF) and Under Frequency (UF). The output from OF and UF are logically AND. The output of FDE or relay under normal case is set at 1 , otherwise 0 (for tripping). The complete block diagram of the FDE is shown in Fig. 4.

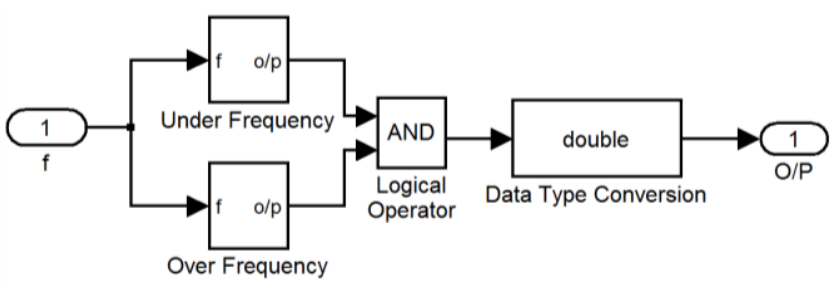

Fig. 4. Frequency Detection Element

The relay setting is given in Table 1 . These limits are generalized and could be set to some other values based on country standards.

TABLE I

FREQUENCY RELAY SETTINGS

\begin{tabular}{cccc}
\hline \hline $\begin{array}{c}\text { Nominal } \\
\text { Frequency }\end{array}$ & $\begin{array}{c}\text { Frequency } \\
\text { Relay }\end{array}$ & Limit & $\begin{array}{c}\text { Threshold } \\
\text { Time }\end{array}$ \\
\hline \multirow{2}{*}{50} & OF & 51 & $5 \mathrm{sec}$ \\
& UF & 48.6 & $5 \mathrm{sec}$ \\
\hline \hline
\end{tabular}

Fig.5 shows the logic diagram for the implementation of a frequency relay in case of an under-frequency situation. The frequency of the voltage signal is first measured by the frequency measuring unit (FMU) and then compared with the threshold under frequency limit i.e. $\mathrm{Fu}(48.6 \mathrm{~Hz})$. If under-frequency condition occurs, the measured frequency ' $\mathrm{f}$ ' less than $\mathrm{Fu}$ ), 1 will be sent to the integrator and integration will occur. The output of the integrator is then compared with the set value of K (5secs). If the integrator output exceeds the $\mathrm{K}$ value, the relay will trip. This is also a check to see the abnormality is transient or continuous. If the abnormality persists for $\mathrm{K}$ seconds the relay trips. Otherwise either integrator is reset by the reset logic or no integration occurs under normal conditions. Under normal condition, the integrator input is set at "0", thus the relay does not operate.

The inside Simulink ${ }^{\circledR}$ model of Under and Over frequency block is shown in Fig. 6 and Fig. 7 respectively. The explanations of the blocks are left to the reader.

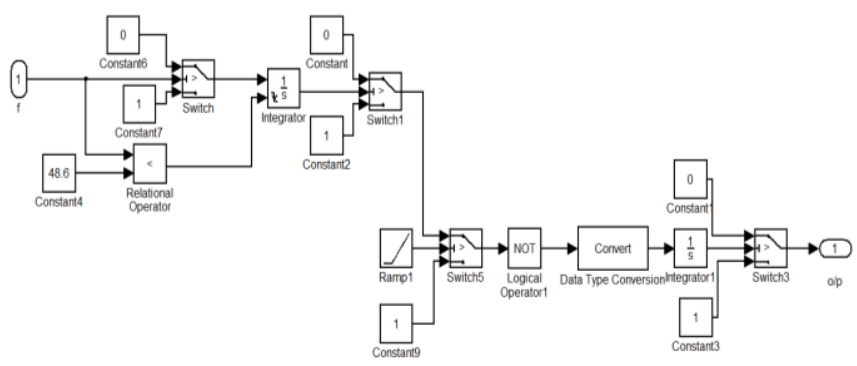

Fig. 6. Under Frequency Detection Block
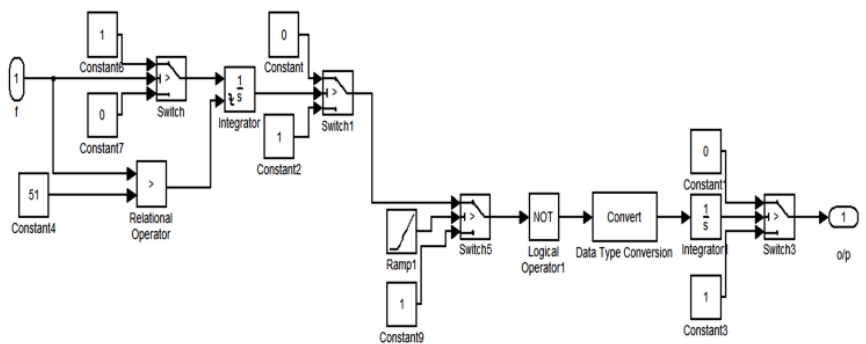

Fig. 7. Over Frequency Detection Block

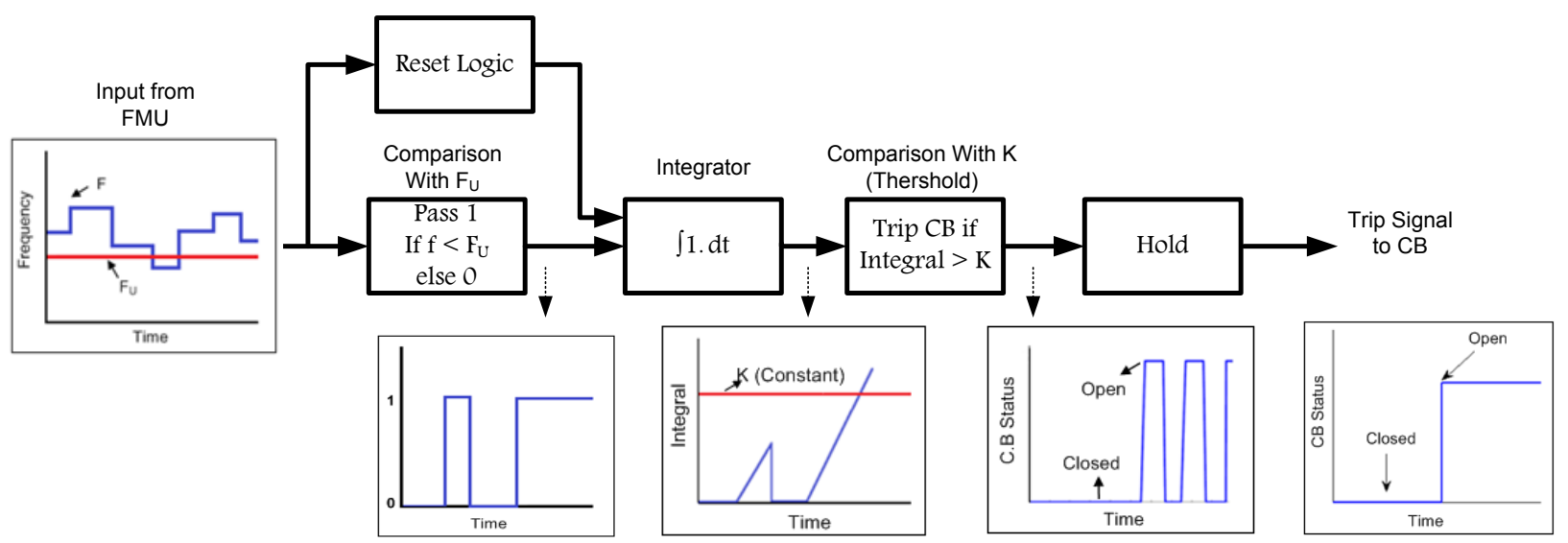

Fig. 5. Logic Diagram for Implementing Under Frequency Block 


\section{Simulations AND RESUlts}

For relay testing and simulation, a $132 \mathrm{kV}$ two bus network is considered. The single line diagram of the network is shown in Fig. 8.

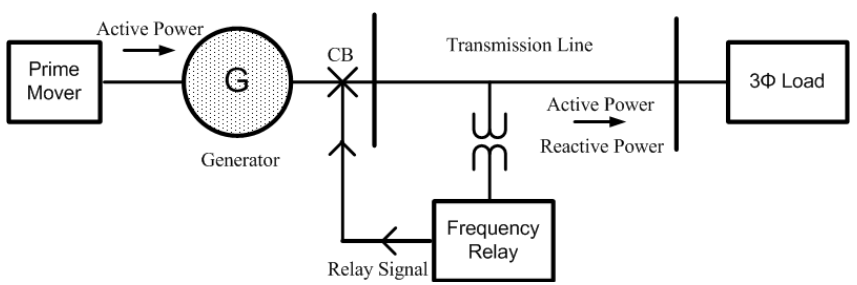

Fig. 8. Single Line Diagram of a Two Bus System

The relay is tested under different test conditions. These tests conditions are given below. Cases 1 and 2 are overfrequency cases, while Cases 3 and 4 are under-frequency cases.

\section{A. Case 1:}

In the first case, the load is shed in two stages. Initially from $190 \mathrm{MW}$ to $150 \mathrm{MW}$ at $70 \mathrm{sec}$, later on further load shed of $70 \mathrm{MW}$ is made at $120 \mathrm{sec}$ and the relay behaviour is observed. Fig. 9 represents the current and relay status under different load conditions.
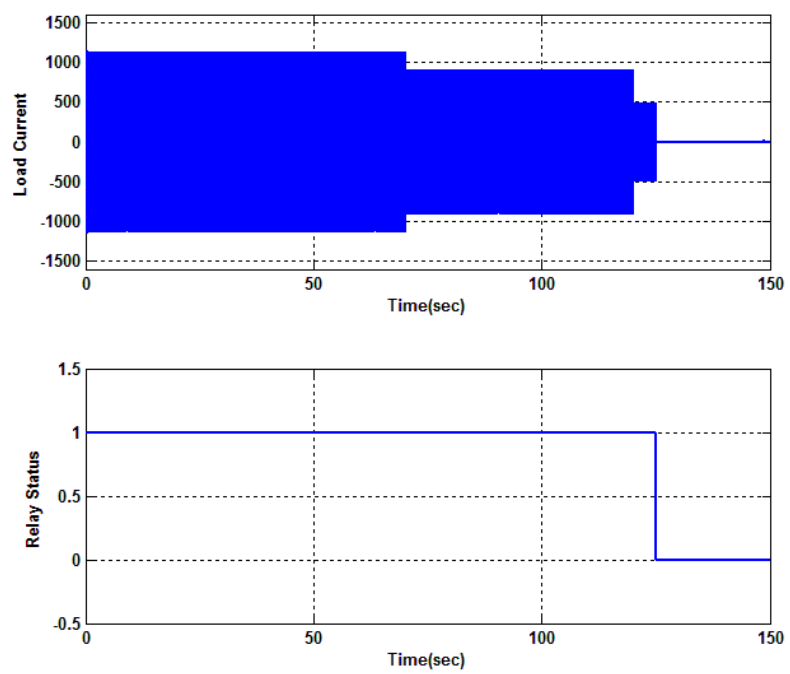

Fig 9. Relay performance (a) Current (b) Relay Status

In first stage the relay does not trip. However a huge decrement in load of $70 \mathrm{MW}$ results in relay tripping. Fig. 10 represents the behaviour of electrical frequency.

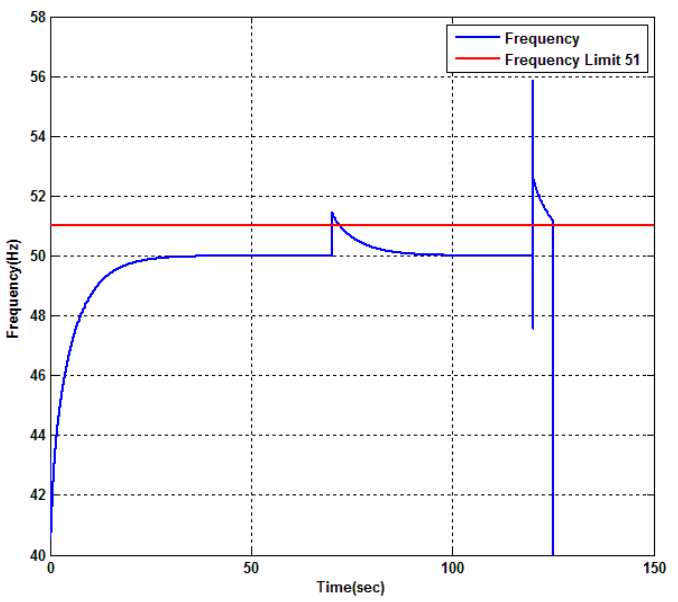

Fig. 10. Output Frequency

\section{B. Case 2:}

In second case, the behaviour of relay under transient condition is observed. One of the load is momentarily disconnects and then restore, within $5 \mathrm{sec}$. In this case, the system load changes from $160 \mathrm{MW}$ to $80 \mathrm{MW}$ at $70 \mathrm{sec}$, however at $75 \mathrm{sec}, 80 \mathrm{MW}$ load restore. Fig. 11 represents the current and relay status under different load conditions.
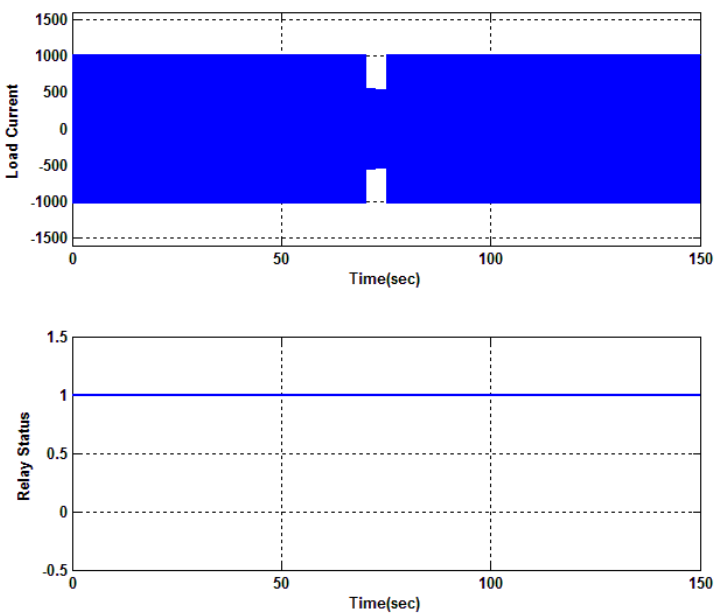

Fig 11. Relay performance (a) Current (b) Relay Status

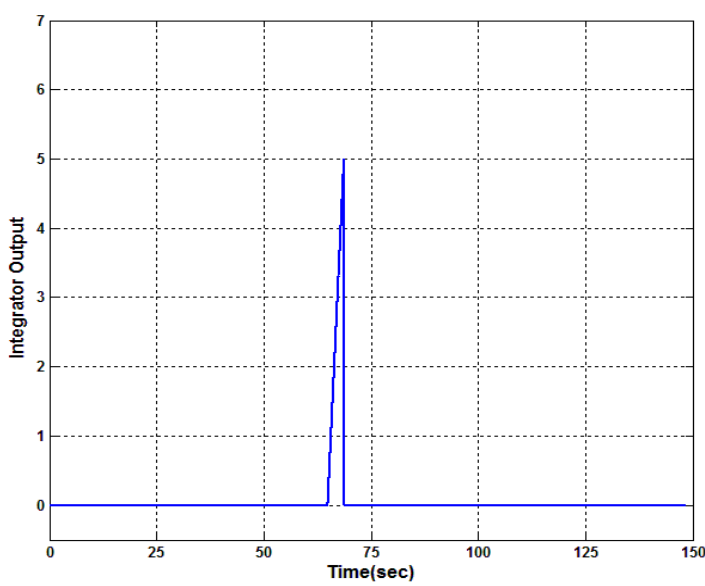

Fig. 12. Integrator Output

Fig. 12 represents the integrator output. Here it could be observed that the integrator try to reaches the 
threshold value of 5. However due to transient conditions, the integrator output could not become greater than 5 , thus the relay does not trip.

\section{Case 3:}

In this case, $40 \mathrm{MW}$ is added at $70 \mathrm{sec}$ in addition to base load of $150 \mathrm{MW}$. Later on further load shed of $50 \mathrm{MW}$ is done at $120 \mathrm{sec}$. Fig. 13 represents the current and relay status under different load conditions.
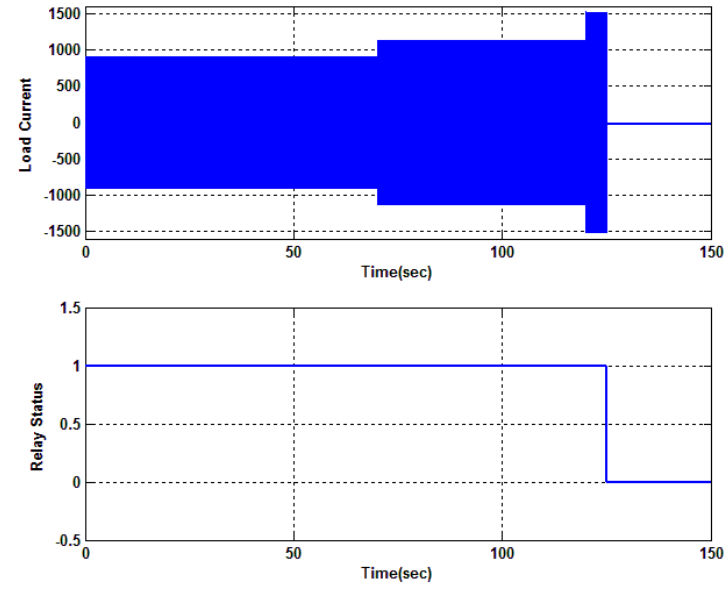

Fig 13. Relay performance (a) Current (b) Relay Status

In first stage the relay does not trip. However a huge increment load of 50MW results in relay tripping. Fig. 14 represents the behaviour of electrical frequency.

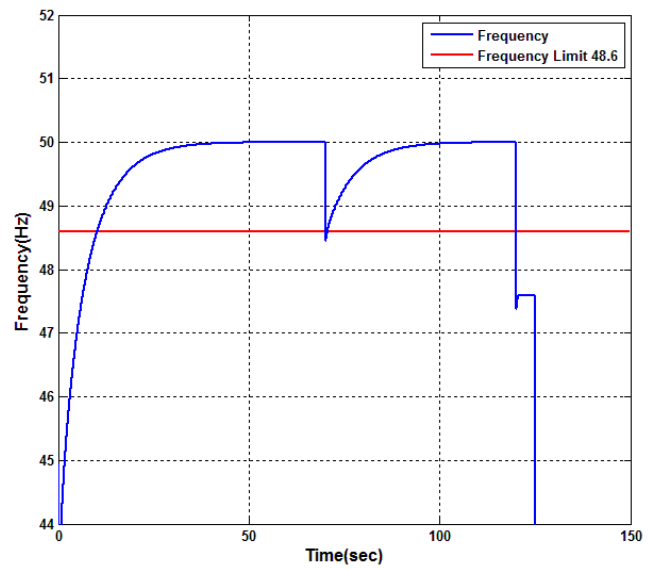

Fig. 14. Output Frequency

\section{Case 4:}

In this case, the behaviour of relay under transient condition is observed. In this case, the system load changes from base case of $150 \mathrm{MW}$ to further addition of $80 \mathrm{MW}$ at $70 \mathrm{sec}$. However at $74 \mathrm{sec}, 80 \mathrm{MW}$ load restore. In second stage $80 \mathrm{MW}$ load is added for indefinite period at $120 \mathrm{sec}$. Fig. 15 represents the current and relay status under different load conditions.
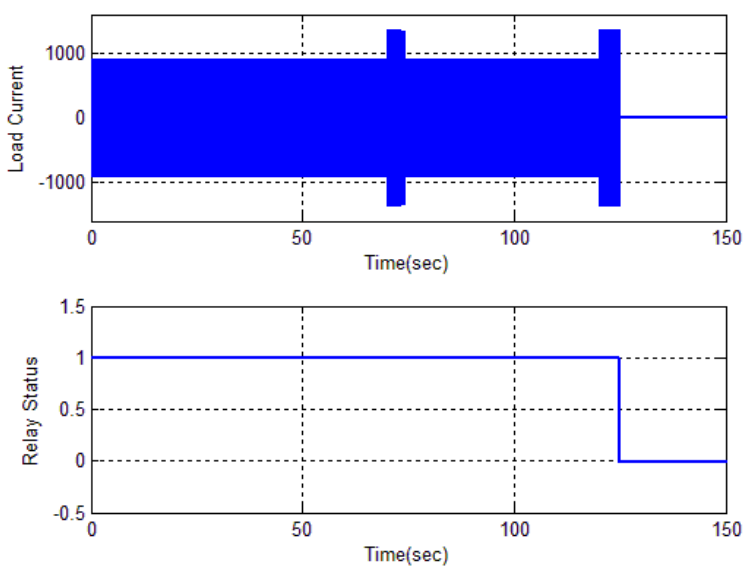

Fig 15. Relay performance (a) Current (b) Relay Status

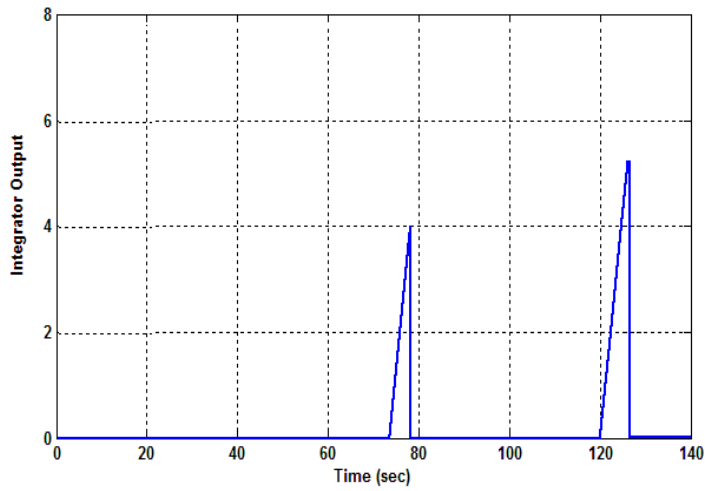

Fig. 16. Integrator Output

Fig. 16 represents the integrator output. Here it could be observed that the integrator try to reaches the threshold value of 5 . However due to transient conditions, the integrator output could not become greater than 5 , thus the relay does not trip. However in second stage, the integrator output reaches the threshold value of 5 and thus the relay trip.

Table II summarizes the relay output summary for all case studies.

TABLE II

RELAY TRIPPED STATUS SUMMARY

\begin{tabular}{|c|c|c|}
\hline $\begin{array}{l}\text { Case } \\
\text { No. }\end{array}$ & Event & $\begin{array}{c}\text { Relay Tripped } \\
\text { Status }\end{array}$ \\
\hline \multicolumn{3}{|c|}{ Over Frequency } \\
\hline 1 & $\begin{array}{l}\text { Load is shed from } 190 \mathrm{MW} \text { to } 150 \mathrm{MW} \\
\text { at } 70 \mathrm{sec} \text {. } \\
\text { Later on, at } 120 \mathrm{sec} \text {, further load shed of } \\
70 \mathrm{MW} \text { is made. }\end{array}$ & $\begin{array}{l}\text { No } \\
\text { Yes }\end{array}$ \\
\hline 2 & $\begin{array}{l}\text { Load shed from } 160 \mathrm{MW} \text { to } 80 \mathrm{MW} \text { at } \\
70 \mathrm{sec} \text {, momentarily for } 4 \text { seconds. } \\
\text { However at } 75 \mathrm{sec}, 80 \mathrm{MW} \text { load restore. }\end{array}$ & No \\
\hline \multicolumn{3}{|c|}{ Under Frequency } \\
\hline 3 & $\begin{array}{l}40 \mathrm{MW} \text { load is added to base load of } \\
150 \mathrm{MW} \text {. } \\
\text { Further load shed of } 50 \mathrm{MW} \text { is done at } \\
120 \text { sec. }\end{array}$ & $\begin{array}{l}\text { No } \\
\text { Yes }\end{array}$ \\
\hline 4 & $\begin{array}{l}\text { Load changes from base case of } \\
150 \mathrm{MW} \text { to further addition of } 80 \mathrm{MW} \\
\text { at } 70 \mathrm{sec} \text {. At } 74 \mathrm{sec}, 80 \mathrm{MW} \text { load } \\
\text { restore. } \\
\text { At } 120 \mathrm{sec}, 80 \mathrm{MW} \text { load is added for } \\
\text { indefinite period. }\end{array}$ & Yes \\
\hline
\end{tabular}




\section{CONCLUSION}

The paper has presented the modelling of the digital frequency relay on MATLAB/SIMULINK $®$. The effectiveness of the proposed relay has been verified by considering different examples as case studies. The complete details of the model with their case studies have also been contributed to MATLAB online resources to support their Power System Tools [12]. The proposed model offer effective means for explaining the behaviours of over-under frequency relay under various operating conditions and changing the design parameters. The digital relay has good advantage in terms of their sensitivity and wide range controlling.

\section{ACKNOWLEDGMENT}

This work was supported by the Bright Spark Programme and the Institute of Research Management and Monitoring Fund -IPPP (Grant Code: PV144/2012A) of University of Malaya-Malaysia.

\section{REFERENCES}

[1] H. Saadat, Power system analysis, 3rd ed.: WCB/McGraw-Hill Singapore, 2010.

[2] M. M. Aman;, et al., "Digital Directional and Non-Directional Over Current Relays: Modelling and Performance Analysis," NED University Journal of Research, vol. 8, 2011.

[3] M. M. Aman, et al., "Modeling and Simulation of Reverse Power Relay for Generator Protection. In 2012 IEEE International Power
Engineering and Optimization Conference (PEOCO2012), Melaka, Malaysia: 6-7 June 2012," 2012.

[4] M. M. Aman, et al., "Modeling and simulation of digital negative sequence relay for unbalanced protection of generator," in Power Engineering and Optimization Conference (PEDCO) Melaka, Malaysia, 2012 Ieee International, 2012, pp. 72-77.

[5] P. Kundur, et al., Power system stability and control vol. 4: McGraw-hill New York, 1994.

[6] A. A. Girgis and F. M. Ham, "A new FFT-based digital frequency relay for load shedding," Power Apparatus and Systems, IEEE Transactions on, pp. 433-439, 1982.

[7] T. Lobos and J. Rezmer, "Real-time determination of power system frequency," Instrumentation and Measurement, IEEE Transactions on, vol. 46, pp. 877-881, 1997.

[8] ABB, "Solid State Under Frequency Relay. Avaialble from: http://www05.abb.com/global/scot/scot229.nsf/veritydisplay/294c23 5c3e25ca9bc1256ed90047c1a1/\$file/sdf-1_ib41-504b.pdf Access on: 10 Sept 2012," 2010.

[9] Areva, "MiCOM P921/P922/P923 Voltage and Frequency Relays (Technical Guide) Available from : ftp://ftp.arevatd.com/P92x_EN_T_F22.pdf."

[10] C. G. Bright, "COROCOF: comparison of rate of change of frequency protection. A solution to the detection of loss of mains," in Developments in Power System Protection, 2001, Seventh International Conference on (IEE), 2001, pp. 70-73.

[11] S. Butler, "UK Electricity Networks The nature of UK electricity transmission and distribution networks in an intermittent renewable and embedded electricity generation future.," 2009.

[12] MATLAB File Exchange. Author: Muhammad Mohsin Aman. Available from: http://www.mathworks.com/matlabcentral/fileexchange/authors/126 622. 